\title{
Thinking too much about the novel coronavirus. The link between persistent thinking about COVID-19, SARS-CoV-2 anxiety and trauma effects
}

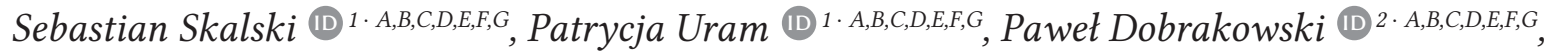 \\ Anna Kwiatkowska (D) $1 \cdot A, B, C, D, E, F, G$ \\ 1: Institute of Psychology, Polish Academy of Sciences, Warsaw, Poland \\ 2: Institute of Psychology, Humanitas University, Sosnowiec, Poland
}

BACKGROUND

Earlier reports have shown that anxiety over the novel coronavirus may predict mental functioning during the pandemic. The objective of this study was to assess the links between persistent thinking about COVID-19, anxiety over SARS-CoV-2 and trauma effects. For the purpose of this study, the Polish adaptation of the Obsession with COVID-19 Scale (OCS) was implemented.

\section{PARTICIPANTS AND PROCEDURE}

The study involved 356 individuals aged $18-78$ ( $58 \%$ females). In addition to OCS, the participants completed the following questionnaires: the Coronavirus Anxiety Scale and the Short Form of the Changes in Outlook Questionnaire.

\section{RESULTS}

OCS was characterized by satisfactory psychometric properties $(\alpha=.82)$. Regression analysis indicated that persis- tent thinking about COVID-19 was associated with increased coronavirus anxiety and negative trauma effects. In addition, anxiety served as a partial mediator in the link between persistent thinking about COVID-19 and negative trauma effects.

\section{CONCLUSIONS}

The data obtained suggest that persistent thinking about the pandemic may be dysfunctional for mental health during the spread of the infectious disease.

\section{KEY WORDS}

persistent thinking; thinking about COVID-19; coronavirus anxiety; trauma effects; Obsession with COVID-19 Scale

CORReSPonding AUthor - Sebastian Skalski, Institute of Psychology, Polish Academy of Sciences, 1 Jaracza Str.,

00-378 Warsaw, Poland, e-mail: sebastian.skalski@sd.psych.pan.pl

AUthors' CONTRiBution - A: Study design - B: Data collection - C: Statistical analysis - D: Data interpretation .

E: Manuscript preparation $\cdot$ F: Literature search $\cdot$ G: Funds collection

to CITE THIS ARTICLE - Skalski, S., Uram, P., Dobrakowski, P., \& Kwiatkowska, A. (2020). Thinking too much about the novel coronavirus. The link between persistent thinking about COVID-19, SARS-CoV-2 anxiety and trauma effects.

Current Issues in Personality Psychology, 8(3), 169-174. 


\section{BACKGROUND}

In March 2020, the World Health Organization (WHO) announced the pandemic of a novel human coronavirus - SARS-CoV-2 (or 2019-nCoV) causing the COVID-19 disease (coronavirus disease 2019) (Guan et al., 2020). Since then, many studies have been undertaken regarding the negative consequences of the pandemic for mental health (Lee, 2020a, 2020b; Skalski, Uram, Dobrakowski, \& Kwiatkowska, 2020; Thakur \& Jain, 2020). The effects were most often related to the sense of loneliness, anxiety and post-traumatic stress disorder (PTSD) symptoms. It should be noted that the nature of the pandemic has led to constant updating of the media on SARS$\mathrm{CoV}-2$, which may have increased the experienced level of anxiety. Excessive consumption of information about the spread of infectious diseases may lead to dysfunctional cognitive processes (persistent thinking) and can be devastating to the mental health of individuals (Lee, 2020b; Taylor, 2019).

Persistent thinking is associated with passive sustained attention to experiencing negative emotions (Langlois, Freeston, \& Ladouceur, 2000). According to Beck, distortions in information processing cause one to absorb the threat and underestimate the ability to cope with it, which ultimately leads to pathological anxiety or distress (Beck, Epstein, Brown, \& Steer, 1988). Research to date has shown that persistent thinking is associated with anxiety over the novel coronavirus, generalized anxiety, and negative trauma effects - PTSD symptoms (Jenness et al., 2016; Lee, 2020b; Lee, Jobe, \& Mathis, 2020).

The objective of this study was to assess the link between persistent thinking about COVID-19, anxiety over SARS-CoV-2 and trauma effects. For the purpose of the study, the Polish adaptation of the Obsession with COVID-19 Scale (OCS) was implemented (Lee, 2020b). We have hypothesized that anxiety over the novel coronavirus may serve as a mediator in the relation between persistent thinking and negative trauma effects (PTSD symptoms). Our hypothesis was based on previous reports, according to which anxiety over the spread of an infectious disease was considered to be an indicator of mental functioning during the pandemic and also buffered the impact of mental variables on the severity of trauma effects (Lee, 2020b; Skalski et al., 2020; Taylor, 2019).

\section{PARTICIPANTS AND PROCEDURE}

\section{PARTICIPANTS}

The study was conducted from April 30 to May 19, 2020 via the Internet. The data were collected on the Google Forms platform. Recruitment was conducted via social media such as Facebook. The study was anonymous and voluntary. Individuals consented to participate in the study and were informed of its objectives and procedure. The study involved 356 individuals aged $18-77(M=37.73, S D=11.76)$, including $58 \%$ females. The participants were diverse in terms of education ( $1 \%$ basic, $1 \%$ middle school, $4 \%$ vocational, $72 \%$ secondary, $22 \%$ higher), residency ( $17 \%$ village, $21 \%$ city up to 100,000 inhabitants, $62 \%$ larger cities) and marital status (28\% single, $63 \%$ in relationships, $7 \%$ divorced, $2 \%$ widowed). The study procedure consisted of filling in questionnaires on persistent thinking about COVID-19, novel coronavirus anxiety and trauma effects.

\section{MEASURES}

Obsession with COVID-19 Scale. For the purposes of the study, the Polish adaptation of Obsession with COVID-19 Scale (OCS; Lee, 2020b) to evaluate persistent thinking about COVID-19 was implemented (adaptation with author's consent). The participants express their attitude towards four statements (see: Supplement 1) on a 5-point Likert scale from 0 (not at all) to 4 (almost every day). The translation process was carried out in accordance with WHO guidelines for cross-cultural research (Juczyński, 2009).

Coronavirus Anxiety Scale. The novel coronavirus anxiety was assessed using the Coronavirus Anxiety Scale (CAS; Lee, 2020a) in its Polish language adaptation (Skalski et al., 2020). The scale consists of five selfdescriptive statements $(\alpha=.86)$. The response manner is coherent with OCS. Sample items: "I lost interest in eating when I thought about or was exposed to information about the coronavirus"; "I felt nauseous or had stomach problems when I thought about or was exposed to information about the coronavirus".

Changes in Outlook Questionnaire. The Short Form of the Changes in Outlook Questionnaire (SF-CiOQ; Joseph, Linley, Shevlin, Goodfellow, \& Butler, 2006) in its Polish standardization (Skalski, 2019) was used to assess the effects of trauma - post-traumatic growth (PTG) and PTSD symptoms. The scale consists of 10 statements arranged according to 2 factors: positive effects $(\alpha=.85)$ and negative effects $(\alpha=.83)$. The participants rate each of them on a 6-point Likert scale from 1 (I strongly disagree) to 6 (I strongly agree). Sample items: "I no longer take people or things for granted"; "I have very little trust in other people now".

\section{STATISTICAL ANALYSES}

The Kolmogorov-Smirnov test was used to assess normal distribution. Levene's test was used to assess homoscedasticity. The scores obtained allowed for application of parametric tests. Exploratory factor 
analysis (EFA) was used to assess the factor structure. Pearson's $r$ correlation analysis and regression analysis were used to determine the relations between the variables. The mediation model was assessed using the Sobel test. The significance level was determined at $p<.05$. The effect size was assessed based on $R^{2}$. Data analysis was conducted in IBM SPSS Statistics 26.

\section{RESULTS}

\section{POLISH ADAPTATION OF OCS}

In order to determine the factor structure of the Polish version of OCS, EFA was conducted using the principal component method with the Kaiser criterion. The results obtained revealed the presence of one component with an eigenvalue exceeding 1 (2.62), accounting for $65.51 \%$ of the variance.

The mean values obtained in individual OCS statements, together with standard deviation and discriminating power of the items, are shown in Table 1 . The strongest symptom of persistent thinking about COVID-19 was disturbing concern over meeting a person infected with SARS-CoV-2, while the weakest symptom involved dreams about the novel coronavirus.

The internal reliability of OCS was assessed based on Cronbach's $\alpha$ which equaled $\alpha=.82$. The con- vergent validity was assessed using the correlation coefficient value with CAS, which equaled $r=.53$ $(p<.001)$. The content validity was assessed by four psychologists using Lawshe's method (1975) - the content validity ratio (CVR) for each statement exceeded the required value of $\mathrm{CVR}>.75$. The next step involved transformation of raw scores into sten scores $(M=5.50, S D=2)$. Temporary sten scores are presented in Supplement 2.

\section{ASSESSMENT OF RELATIONS}

Mean values obtained in OCS, CAS and SF-CiOQ together with standard deviation and correlation coefficient values are shown in Table 2 . Statistically significant relations were observed between anxiety over the novel coronavirus versus persistent thinking about COVID-19; between positive trauma effects versus anxiety; between negative effects of trauma versus persistent thinking and anxiety. In this study, sociodemographic data did not have a statistically significant impact on the controlled variables.

Regression analysis indicated that anxiety over the novel coronavirus acts as a mediator in the link between persistent thinking about COVID-19 and negative trauma effects. The overall effect equaled $\beta=.38\left(t=7.69, p<.001, R^{2}=.14\right)$. The regression coefficient of the independent variable's impact on

Table 1

Mean values obtained in OCS $(N=356)$

\begin{tabular}{lcccc}
\hline & $M$ & $S D$ & $\%$ & $r$ \\
\hline 1. Concern over being infected & 1.61 & 1.32 & 46.91 & $.86^{* * *}$ \\
2. Concern over meeting an infected person & 1.65 & 1.37 & 48.88 & $.84^{* * *}$ \\
3. Intrusive thoughts about the coronavirus & 1.19 & 1.36 & 32.02 & $.84^{* * *}$ \\
4. Dreams involving the coronavirus & 0.63 & 1.14 & 17.13 & $.69^{* * *}$ \\
\hline
\end{tabular}

Note. $M$ - mean, $S D$ - standard deviation, \% - percentage of individuals who gave a rating of "at least a few days within the last 2 weeks" or higher (2, 3, 4 points), $r$ - discriminating power (correlation coefficient with overall OCS score); ${ }^{* * *} p<.001$ (level of significance).

Table 2

Mean values obtained in the test and the correlation value $(N=356)$

\begin{tabular}{|c|c|c|c|c|c|c|}
\hline & \multirow[t]{2}{*}{$M$} & \multirow[t]{2}{*}{$S D$} & \multicolumn{4}{|c|}{$r$} \\
\hline & & & 1. & 2. & 3. & 4. \\
\hline 1. Persistent thinking about COVID-19 & 5.08 & 4.21 & 1 & & & \\
\hline 2. Coronavirus anxiety & 3.90 & 4.59 & $.53^{* * *}$ & 1 & & \\
\hline 3. Positive trauma effects & 15.35 & 5.28 & -.10 & $-.16^{* *}$ & 1 & \\
\hline 4. Negative trauma effects & 12.85 & 5.97 & $.38^{* * *}$ & $.51^{* * *}$ & -.09 & 1 \\
\hline
\end{tabular}

Note. $r$ - correlation coefficient, ${ }^{* *} p<.01,{ }^{* * *} p<.001$ (level of significance). For other elements see Table 1. 


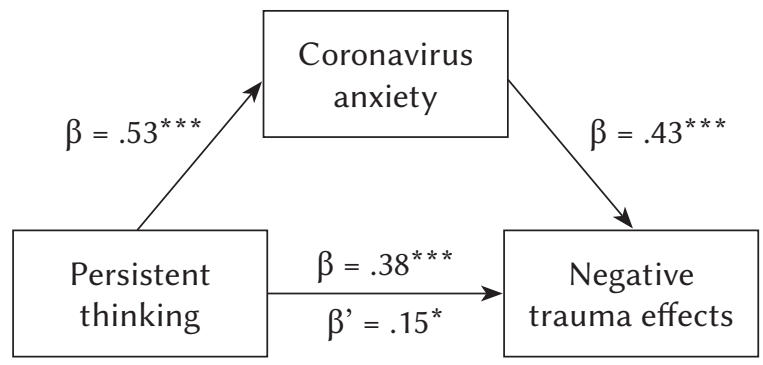

Note. $\beta$ - standardized regression factor, ${ }^{*} p<.05,{ }^{* * *} p<.001$ (significance level).

Figure 1. Coronavirus anxiety as a mediator in the link between persistent thinking about COVID-19 and negative trauma effects $(N=356)$.

the mediator was $\beta=.53\left(t=11.90, p<.001, R^{2}=.29\right)$. The regression coefficient of the mediator's impact on the dependent variable, with a simultaneous control of the independent variable, equaled $\beta=.43(t=7.93$, $p<.001, R^{2}$ for the entire model $\left.=.27\right)$. Mediation weakened the relation between persistent thinking about COVID-19 and the negative trauma effects the direct effect was $\beta^{\prime}=.15(t=2.81, p=.005)$. The partial mediation model was confirmed by the Sobel test score $z=6.58(S E=.05, p<.001)$. Figure 1 depicts the mediation design.

\section{DISCUSSION}

The purpose of this study was to assess the links between persistent thinking about COVID-19, coronavirus anxiety and trauma effects. For the purposes of this study, the Polish OCS adaptation was conducted.

OCS in its Polish version exhibited satisfactory psychometric values. The scale may be used to assess the intensity of persistent thoughts in connection with the novel coronavirus pandemic in clinical diagnosis and scientific research. In the adaptive study, we did not assess the absolute stability of OCS, as the construct should be considered as a form of intensity that can change under the influence of interventions.

Persistent thinking about COVID-19 was revealed to be associated with increased coronavirus anxiety and negative trauma effects (PTSD symptoms). In addition, SARS-CoV-2 anxiety proved to be a partial mediator in the link between persistent thinking and negative trauma effects. In other words, people who felt persistent concern over COVID-19 were more likely to experience clinical symptoms of coronavirus anxiety, which elevated the negative trauma effects. It should be noted that a regression model taking into account the mediator (anxiety) allowed for explaining much greater variance of negative trauma effects $(27 \%)$ than persistent thinking alone (14\%). Our findings are in line with previous reports in this respect (Jenness et al., 2016; Lee, 2020b; Lee et al., 2020; Skalski et al., 2020; Taylor, 2019). Moreover, Lee et al. (2020) observed that persistent thinking about COVID-19 can lead to abuse of psychoactive substances, depressive symptoms or suicidal ideation. Finally, it should be stressed that persistent thinking about COVID-19 may in the future (in some people) progress to deliberate rumination and contribute to the development of PTG (Ogińska-Bulik \& Juczyński, 2016; Soo \& Sherman, 2015).

Positive trauma effects (i.e. PTG) were also assessed in this study. The variable turned out to be negatively correlated with coronavirus anxiety (small effect). However, it should be noted that PTG develops over time under the influence of coping strategies (Calhoun \& Tedeschi, 2006).

This study is affected by certain limitations. The cross-sectional nature of the study does not allow for an effective judgment concerning the causes and effects. In addition, some constructs seem to be interconnected, e.g. persistent thinking leads to increased coronavirus anxiety, whereas anxiety may be related to a sense of helplessness and can reinforce the occurrence of persistent thoughts. In addition, the study did not control exposure to the SARS-CoV-2 infection, which may affect the obtained results. In future studies, it would seem interesting to identify the factors that moderate persistent thinking about COVID-19, e.g. assessment of exposure to information or involvement in internet media.

This is one of the first studies to evaluate the relationship between persistent thinking about COVID-19, coronavirus anxiety and trauma effects. The obtained model indicates an important role of cognitive involvement in the onset of negative posttraumatic changes. We have indicated that persistent thinking about the pandemic may be dysfunctional for mental health during the spread of the infectious disease. The data obtained have an application value and can be considered when developing prevention programs.

\section{REFERENCES}

Beck, A. T., Epstein, N., Brown, G., \& Steer, R. A. (1988). An inventory for measuring clinical anxiety: Psychometric properties. Journal of Consulting and Clinical Psychology, 56, 893-897. https:// doi.org/10.1037/0022-006X.56.6.893

Calhoun, L., \& Tedeschi, R. (2006). The foundations of posttraumatic growth: an expanded framework. In L. Calhoun \& R. Tedeschi (Eds.), Handbook of posttraumatic growth: Research \& practice (pp. 3-23). Mahwah, NJ: Lawrence Erlbaum Associates Publishers.

Guan, W., Ni, Z., Hu, Y., Liang, W., Ou, C., He, J., ... Zhong, N. (2020). Clinical characteristics of corona- 
virus disease 2019 in China. New England Journal of Medicine, 382, 1708-1720. https://doi.org/10.1056/ NEJMoa2002032

Jenness, J. L., Jager-Hyman, S., Heleniak, C., Beck, A. T., Sheridan, M. A., \& McLaughlin, K. A. (2016). Catastrophizing, rumination, and reappraisal prospectively predict adolescent PTSD symptom onset following a terrorist attack. Depression and Anxiety, 33, 1039-1047. https://doi.org/10.1002/da.22548

Joseph, S., Linley, P. A., Shevlin, M., Goodfellow, B., \& Butler, L. (2006). Assessing positive and negative changes in the aftermath of adversity: a short form of the Changes in Outlook Questionnaire. Journal of Loss and Trauma, 11, 85-99. https://doi. org/10.1080/15325020500358241

Juczyński, Z. (2009). Narzędzia pomiaru w promocji i psychologii zdrowia [Measurement tools in health promotion and psychology]. Warsaw: Pracownia Testów Psychologicznych PTP.

Langlois, F., Freeston, M. H., \& Ladouceur, R. (2000). Differences and similarities between obsessive intrusive thoughts and worry in a non-clinical population: Study 1. Behaviour Research and Therapy, 38, 157-173. https://doi.org/10.1016/S0005-7967 (99)00027-3

Lawshe, C. (1975). A quantitative approach to content validity. Personnel Psychology, 28, 563-575. https://doi.org/10.1111/j.1744-6570.1975.tb01393.x

Lee, S. A. (2020a). Coronavirus Anxiety Scale: a brief mental health screener for COVID-19 related anxiety. Death Studies, 44, 393-401. https://doi.org/10. 1080/07481187.2020.1748481

Lee, S. A. (2020b). How much "thinking" about COVID-19 is clinically dysfunctional? Brain, Behavior, and Immunity, 87, 97-98. https://doi.org/10.1016/j. bbi.2020.04.067

Lee, S. A., Jobe, M. C., \& Mathis, A. A. (2020). Mental health characteristics associated with dysfunctional coronavirus anxiety. Psychological Medicine, 1-2. https://doi.org/10.1017/S003329172000121X

Ogińska-Bulik, N., \& Juczyński, Z. (2016). Ruminations as predictors of negative and positive effects of experienced traumatic events in medical rescue workers. Medycyna Pracy, 67, 201-211. https://doi. org/10.13075/mp.5893.00321

Skalski, S. (2019). New perspective questionnaire to measure positive and negative trauma effects. Polish adaptation of the Short Form of the Changes in Outlook Questionnaire. Annales Universitatis Mariae Curie-Skłodowska, Sectio J - PaedagogiaPsychologia, 32, 307-317. https://doi.org/10.17951/ j.2019.32.3.307-317

Skalski, S., Uram, P., Dobrakowski, P., \& Kwiatkowska, A. (2020). The link between ego-resiliency, social support, SARS-CoV-2 anxiety and trauma effects. Polish adaptation of the Coronavirus Anxiety Scale. Manuscript submitted for publication. https://doi.org/10.31234/osf.io/28tnw
Soo, H., \& Sherman, K. A. (2015). Rumination, psychological distress and post-traumatic growth in women diagnosed with breast cancer. Psycho-Oncology, 24, 70-79. https://doi.org/10.1002/pon.3596

Taylor, S. (2019). The psychology of pandemics: Preparing for the next global outbreak of infectious disease. Newcastle upon Tyne, UK: Cambridge Scholars Publishing.

Thakur, V., \& Jain, A. (2020). COVID 2019-suicides: a global psychological pandemic. Brain, Behavior, and Immunity. https://doi.org/10.1016/ j.bbi.2020.04.062 


\section{SUPPLEMENT 1}

\section{OCS statements in Polish}

Jak często w trakcie ostatnich 2 tygodni doświadczyłeś/aś poniższych zdarzeń? [How often have you experienced the following activities over the last 2 weeks?]

1. Obawiałem/am się, że mogłem/am zostać zakażony/a koronawirusem [I had disturbing thoughts that I may have caught the coronavirus].

2. Obawiałem/am się, że ludzie, których spotkałem/am, są nosicielami koronawirusa [I had disturbing thoughts that certain people I saw may have the coronavirus].

3. Nie mogłem/am przestać myśleć na temat koronawirusa [I could not stop thinking about the coronavirus].

4. Miałem/am sny na temat koronawirusa [I dreamed about the coronavirus].

\section{Supplement 2}

Temporary sten scores for OCS $(N=356)$

\begin{tabular}{lc}
\hline RS & Sten \\
\hline 0 & 1 \\
1 & 2 \\
2 & 3 \\
3 & 4 \\
4 & 5 \\
$5-6$ & 6 \\
$7-9$ & 7 \\
$10-12$ & 8 \\
$13-14$ & 9 \\
$15-16$ & 10 \\
\hline Note. RS - raw score. &
\end{tabular}

